\title{
Multiple Sclerosis Epidemiology in Middle East and North Africa: A Systematic Review and Meta-Analysis
}

\author{
Pouria Heydarpour ${ }^{\mathrm{a}}$ Shayan Khoshkish ${ }^{\mathrm{a}}$ Shabnam Abtahi ${ }^{\mathrm{a}} \quad$ Maziar Moradi-Lakeh $^{\mathrm{b}}$ \\ Mohammad Ali Sahraian ${ }^{a}$ \\ ${ }^{a}$ MS Research Center, Neuroscience Institute, Tehran University of Medical Sciences, and ${ }^{b}$ Department of Community \\ Medicine, Iran University of Medical Sciences, Tehran, Iran
}

\section{Key Words}

Multiple sclerosis - Epidemiology · Prevalence - Middle East · North Africa

\begin{abstract}
Background: Multiple sclerosis (MS) is one of the most common neurological disorders and a leading cause of nontraumatic disability in young adults in many countries. Recent reports from the Middle East and North Africa have suggested a moderate to high risk of MS in these countries. Methods: A literature search was performed in August 2014 in MEDLINE, EMBASE, and IMEMR to retrieve original population-based studies on MS epidemiology in the Middle East and North African countries published between 1st January 1985 and 1st August 2014. We designed search strategies using the key words: MS, prevalence, incidence, and epidemiology. According to the inclusion criteria, 52 studies were included in this systematic review. Results: McDonald's criteria were the most widely used diagnostic criteria in the studies. Most studies were conducted in single hospitalbased centers with a defined catchment area. The female/ male ratio ranged from 0.8 in Oman to 4.3 in Saudi Arabia.
\end{abstract}

MS prevalence ranged from $14.77 / 100,000$ population in Kuwait (2000) to $101.4 / 100,000$ in Turkey (2006). The overall MS prevalence in the region was $51.52 / 100,000$. The mean age at disease onset ranged from 25.2 years in Kuwait to 32.5 years in Northeastern Iran, with an overall estimate of 28.54 years. Conclusions: Recent advances in MS registries will allow nation-wide studies and temporal comparisons between countries, provided that age- and sex-standardized estimates are available.

(c) 2015 S. Karger AG, Basel

\section{Background}

Multiple sclerosis (MS) is an inflammatory demyelinating and neurodegenerative disease affecting more than 2 million people worldwide [1]. MS may have a variable clinical course; episodic acute periods of relapses, gradual progressive decline of neurologic function, or combinations of both [2]. MS typically begins in early adulthood;

P.H. and S.K. are equal first author contributors.

\section{KARGER 125}

(c) 2015 S. Karger AG, Base

0251-5350/15/0444-0232\$39.50/0

E-Mail karger@karger.com

www.karger.com/ned
Prof. Mohammad Ali Sahraian

MS Research Center, Neuroscience Institute

Tehran University of Medical Sciences

Tehran (Iran)

E-Mail msahrai@tums.ac.ir 
Fig. 1. Flow diagram of studies based on the PRISMA statement.

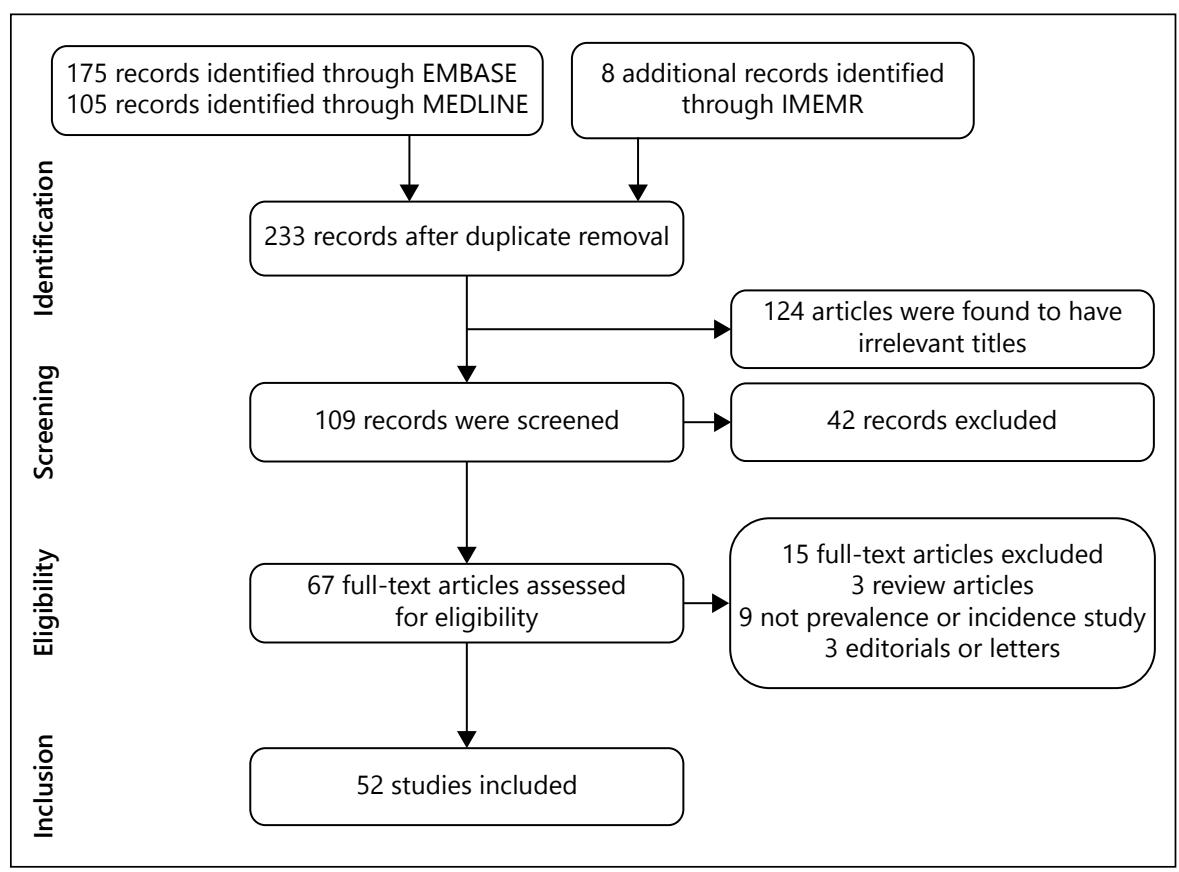

15 years after the onset of disease, up to 50 percent of patients will need help in walking [3]. An almost universal increase in prevalence and incidence of MS over time with a general increase in the incidence of MS in females has been observed in meta-analyses of studies on MS epidemiology since 1965 [4]. A longitudinal study in Canada over the past 50 years suggests that different smoking habits could explain the increase in the female/male sex ratio [5].

Middle Eastern and North African countries are located in a low- to moderate-risk zone for MS based on the 2013 MS Atlas [6]; however, recent studies suggest a moderate-to-high prevalence in areas within this region, with an increase in the incidence and prevalence especially among women [7-11]. Increasing burden of MS in Middle Eastern countries, in addition to high costs of managing this condition, denotes a special notice to reliable epidemiological data for healthcare planning and policymaking purposes.

Disparities in environmental risk factors and genetic predispositions modulate the risk of MS at the population level [12]. Studying changes in the incidence and prevalence could reveal temporal and spatial patterns contributing to variable MS risk across populations. Given the limited epidemiological data on MS in Middle East and North African countries, this systematic review aims to pool all available data to elucidate trends in the incidence, prevalence, and natural history of MS in these countries.

MS Epidemiology in Middle East and North Africa

\section{Materials and Methods}

\section{Screening and Eligibility Criteria}

The following criteria were used to select papers for inclusion in this systematic review: (1) the population defined primarily as those living in Middle Eastern/North African countries; our definition of the Middle East and North African countries was based on the global burden of diseases definition of North Africa and the Middle East region, including the following 21 countries: Algeria, Bahrain, Egypt, Iran, Iraq, Jordan, Kuwait, Lebanon, Libya, Morocco, Oman, Palestine, Qatar, Saudi Arabia, Sudan, Syria, Tunisia, Turkey, United Arab Emirates, Western Sahara, and Yemen [13]. (2) MS was defined according to accepted international diagnostic criteria in use at the time of the study (Poser et al. [14] or McDonald's criteria) [15-17]. (3) The prevalence, incidence, or number of MS cases were reported in the study. (4) Articles in English language were included in this study. We excluded articles primarily focusing on other fields of MS: neuroimaging, neuroimmunology, and not providing estimates on MS prevalence. Studies before 1985, when magnetic resonance imaging (MRI) became a part of clinical practice and substantially influenced the diagnosis of MS, were few in this region and we have incorporated this exclusion criteria similar to other systematic reviews on MS epidemiology in other regions [18-20]. We did not include Israel in our study because WHO considered it as a high-income European country; thus, it is beyond the scope of this review $[21,22]$.

The flow diagram of study selection was developed according to PRISMA statement (fig. 1).

\section{Search Strategy}

We have queried the MEDLINE, EMBASE, and IMEMR with the following keywords: 'MS', 'incidence', 'prevalence', and 'epidemiology'. Our search strategy is provided in the online supplemen- 
tary files (for all online suppl. material, see www.karger.com/ doi/10.1159/000431042). We also did a manual search of reference lists from primary articles and relevant reviews.

Quality Assessment and Data Extraction

Two independent reviewers (P.H. and S.K.) used the Joanna Briggs Institute critical appraisal tools to assess the methodological quality of each study [23]. If the two reviewers disagreed on the final critical appraisal and this could not be resolved through discussion, a third reviewer's opinion was sought (S.A.). Quality scores of the studies are presented in detail in online supplementary table 1. A trained reviewer extracted following data into a standardized form: the study period, location, diagnostic criteria, number of cases, female/male ratio, average age of the study population, mean age at disease onset, and MS subtype proportions. Crude and standardized prevalence and incidence estimates were documented overall and by sex, region, time period, and subgroup as applicable.

\section{Statistical Analysis}

Meta-analysis was performed for pooled data for prevalence, mean age at disease onset, female proportion of patients, and MS subtype proportions using STATA software version 13 (Stata Corp., College Station, Tex., USA). A moment-based random model was used for estimating pooled measures because of heterogeneity of studies. We used metaregression to find trend of changes in the above-mentioned variables over time.

\section{Results}

Our literature review resulted in 233 studies after duplicate removals. Among these studies, 124 studies had irrelevant titles and 42 studies did not pass the eligibility criteria during the abstract/full-text screening. Finally, we included 52 studies in this systematic review (fig. 1). Table 1 shows the study period, type, location, diagnostic criteria, number of cases, female/male ratio, mean age at disease onset, prevalence rates, incidence rates, and quality scores in these studies.

Our search on epidemiology of MS in Middle East and North African countries yielded no results in Bahrain, Morocco, Palestine, Syria, Western Sahara, and Yemen. Single hospital-based studies covering mainly capital cities were the only source of information on MS epidemiology in UAE, Saudi Arabia, Qatar, Oman, Lebanon, Iraq, and Algeria. We have presented these studies separately in table 2. Detailed quality scores of studies included in this systematic review are presented in online supplementary tables 1 and 2 .

McDonald's criteria were the most widely used diagnostic criteria (44\%), Poser et al. criteria were used in $36 \%$ of studies. The 2005 revision of McDonald's criteria was used in $14 \%$, while the 2010 revision was only used in two studies and Schumacher and McAlpine criteria were used in one study.

Community-based surveys were conducted in $7 \%$ of the studies to estimate the prevalence of MS [24-27]. Regional MS registries were used as the data source to obtain patient records in 30\% of studies [7-9, 28-40], while single hospital-based studies accounted for $34 \%$ of studies $[10,41-57]$ and $23 \%$ of studies were conducted in a multicenter hospital-based setting [11, 58-68]. One study used the ministry of health data for interferon therapy as the data source [69].

The female/male sex ratio varied among studies in the region, ranging from 0.8 in Oman [50] to 4.3 in Saudi Arabia [54]. The overall pooled estimate of female proportion of MS patients was $0.67(0.65-0.69)$ and this proportion slightly increased over time (Coef. $0.004, \mathrm{p}=0.03$; fig. 2).

Study methodologies and the quality of the methods can influence the estimates of prevalence rates in epidemiological studies; figure 3 depicts the heterogeneity of prevalence rates (with confidence intervals) in this region. Prevalence rates range from $14.77 / 100,000$ in Kuwait (2005 [46]) to 101.4/100,000 in Turkey (2006 [27]). Meta-analysis of the pooled estimates are presented in table 3, an overall prevalence of 51.52/100,000 (36.10$66.95 / 100,000)$ was estimated for countries in this region (heterogeneity statistic $=4,835.85, \mathrm{I}^{2}=99.8 \%$ ). A metaregression analysis showed a significant increase in MS prevalence in this region over time (Coef. 2.89, $\mathrm{p}=0.03$ ).

The annual MS incidence rate in the Middle East and North African countries was only reported in few studies ranging from 0.8 in Libya (1985 [65]) to 9.1/100,000 in Isfahan (2011 [7]). The 3-year incidence rate in Isfahan was reported to be 26.03/100,000 in a later study (2013 [9]).

The mean age at disease onset was similar in these countries, ranging from 25.2 in Kuwait [64] to 32.5 in Northeastern Iran [38]. Figure 4 demonstrates studies reporting the mean age at disease onset. Meta-analysis revealed an overall mean age at the onset of 28.54 years for MS patients (27.61-29.48); the age at disease onset did not change significantly over time (Coef. 0.09, $\mathrm{p}=0.23$ ).

Several studies reported the following course of disease in patients: relapsing-remitting MS (RRMS), secondary-progressive MS (SPMS), primary-progressive MS (PPMS), and relapsing-progressive MS (RPMS). The overall proportions of these MS subtypes are presented in table 4. We only found a slight decrease in PPMS in the region over time (Coef. $-0.006, \mathrm{p}=0.01$ ).

Age- and sex-specific prevalence rates were reported in few studies; as these measures provide the most useful estimates to compare MS among countries, we have pro- 


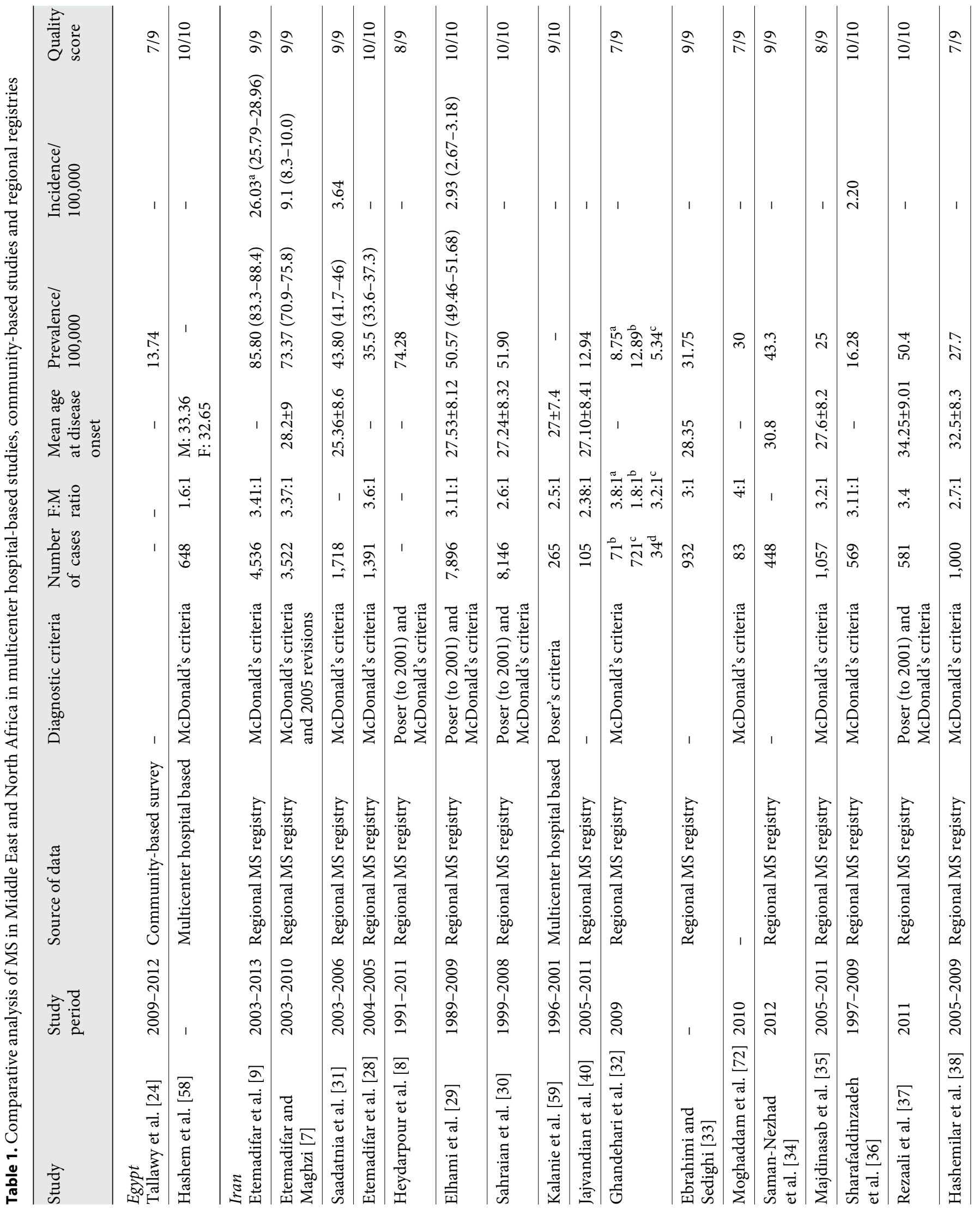




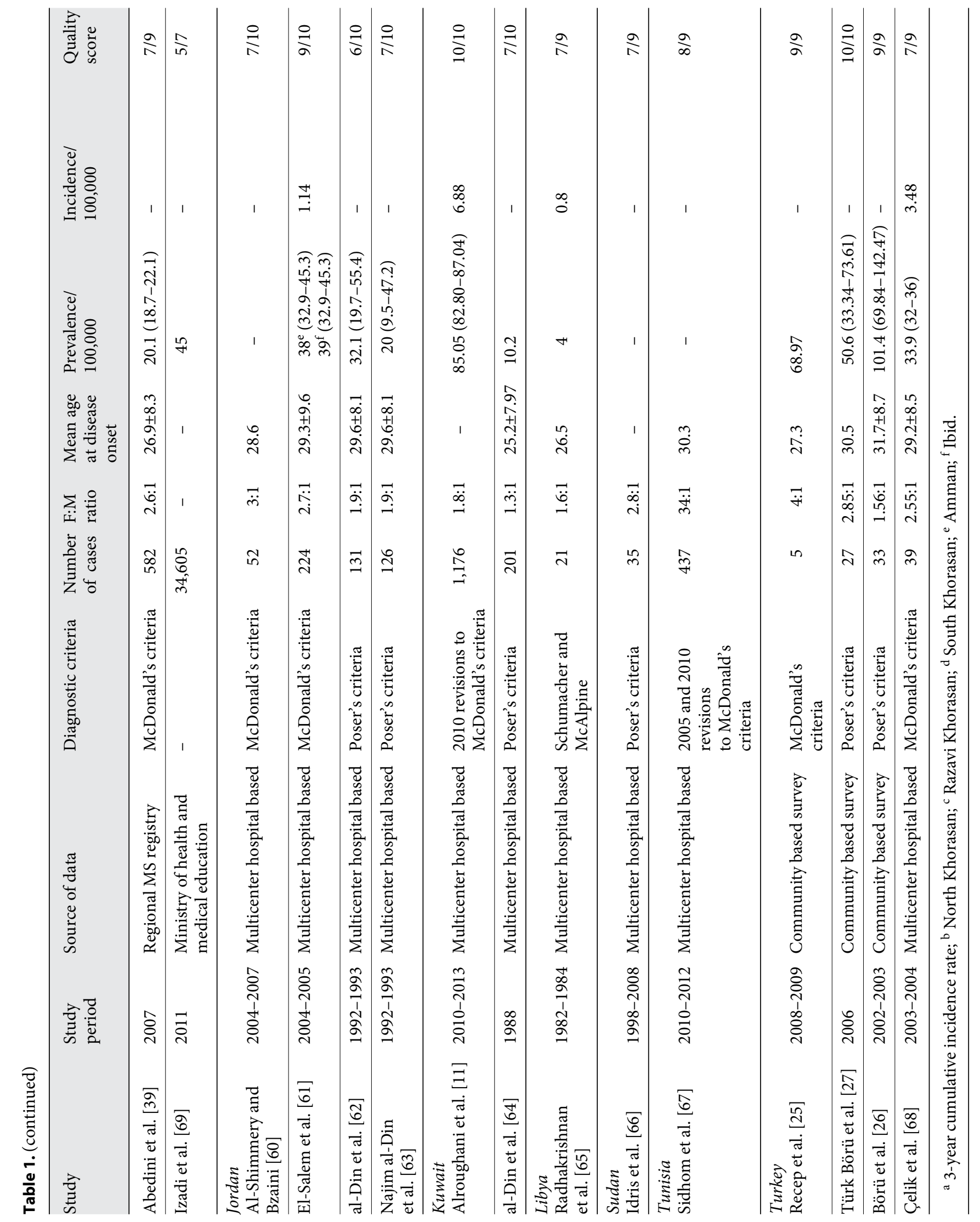




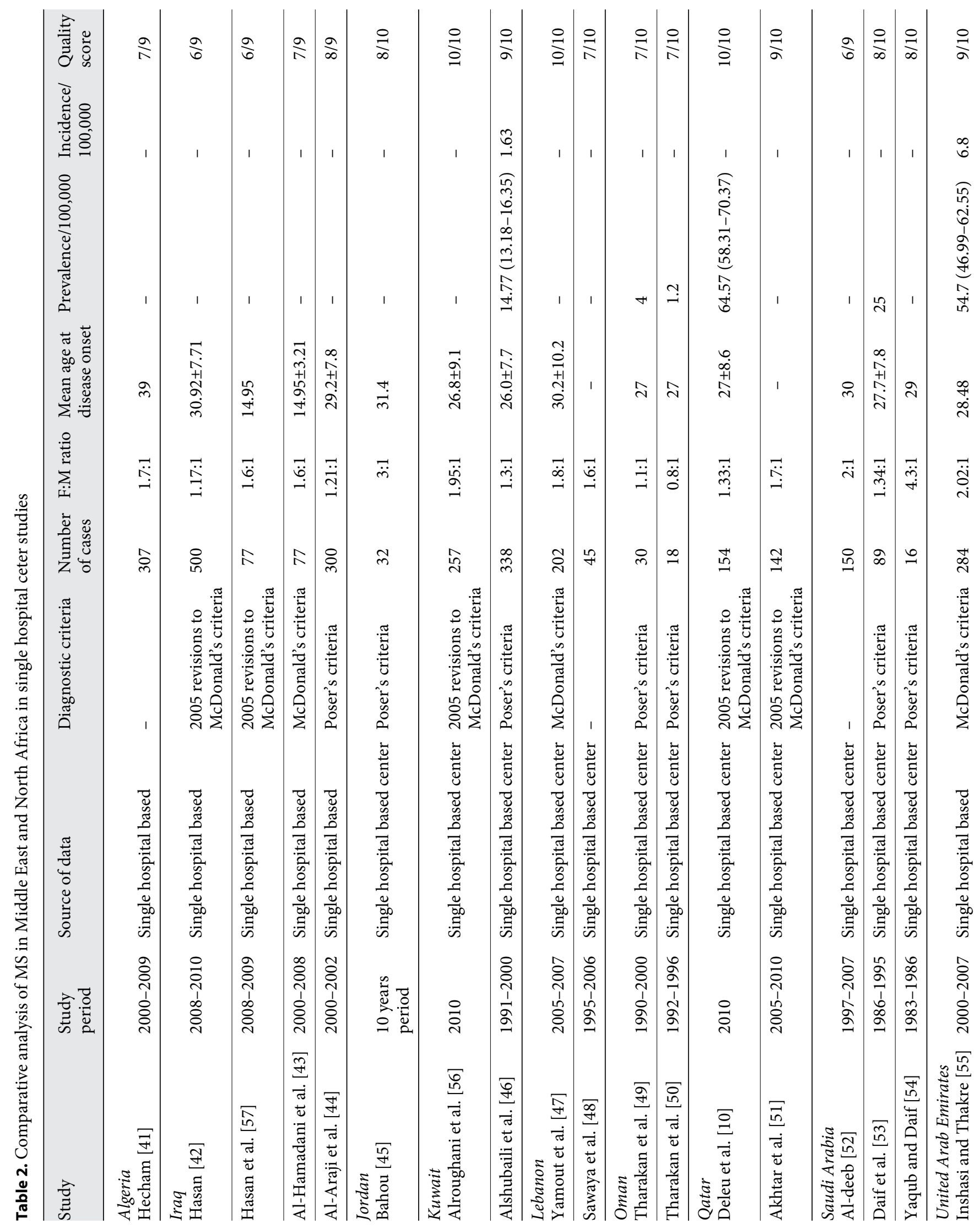




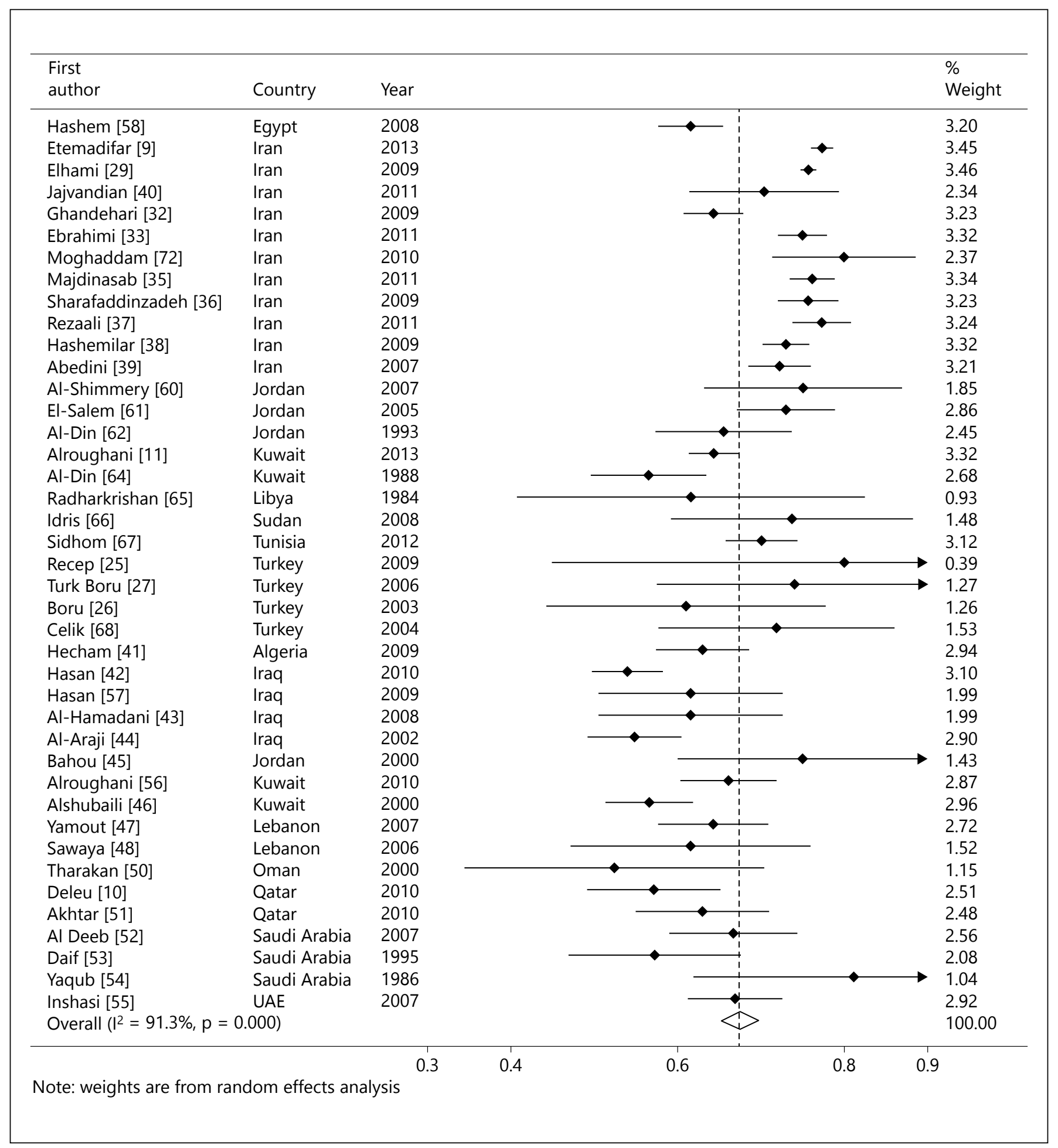

Fig. 2. Female proportion of MS patients in studies from Middle East and North Africa. 


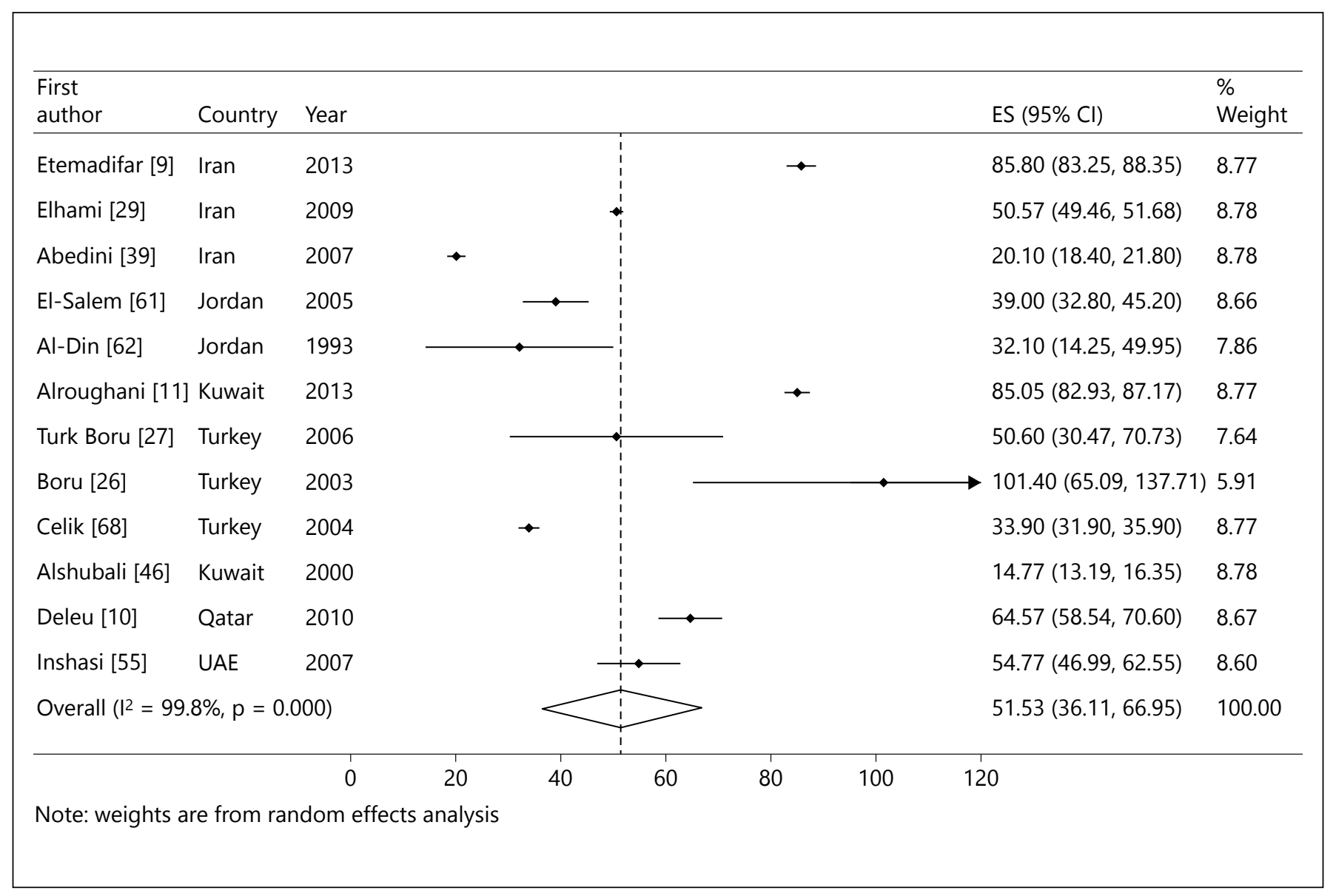

Fig. 3. Prevalence of of MS in studies from Middle East and North Africa.

Table 3. Meta-analysis of the pooled estimates for prevalence, mean age at disease onset, and female proportion of patients

\begin{tabular}{|c|c|c|c|c|c|c|c|}
\hline Overall estimate & Pooled estimate & Lower limit & Upper limit & $\begin{array}{l}\text { Heterogeneity } \\
\text { statistic }\end{array}$ & Degrees of freedom & $\mathrm{p}$ value & $\mathrm{I}^{2}, \%$ \\
\hline Prevalence & 51.52 & 36.10 & 66.95 & $4,835.85$ & 11 & 0.000 & 99.8 \\
\hline Mean age at onset & 28.54 & 27.61 & 29.48 & 487.96 & 15 & 0.000 & 96.9 \\
\hline Female proportion & 0.67 & 0.65 & 0.69 & 459.38 & 40 & 0.000 & 91.3 \\
\hline
\end{tabular}

vided them in online supplementary table 3 . We have also presented the annual number of cases (incidence data) by the calendar year of onset in online supplementary table 4 .

A brief description of the epidemiology and natural history of MS in each country is presented here:

\section{Algeria}

MS has been scarcely documented in Algeria, 307 patients were reported to have MS in a single hospital-based study. Most patients experienced motor symptoms as the presenting symptom (73.6\%); RRMS was reported in $61.9 \%$, secondary progressive in $19.5 \%$, and progressive in $18.6 \%$ patients [ 41$]$.

\section{Egypt}

A community-based survey in Al Quseir, Egypt, has found an MS prevalence of 13.74/100,000 [24]. A retrospective meta-analysis in different referral centers of Egypt has found 648 patients with definite MS. The most frequent presenting symptom was weakness (57\%), fol- 


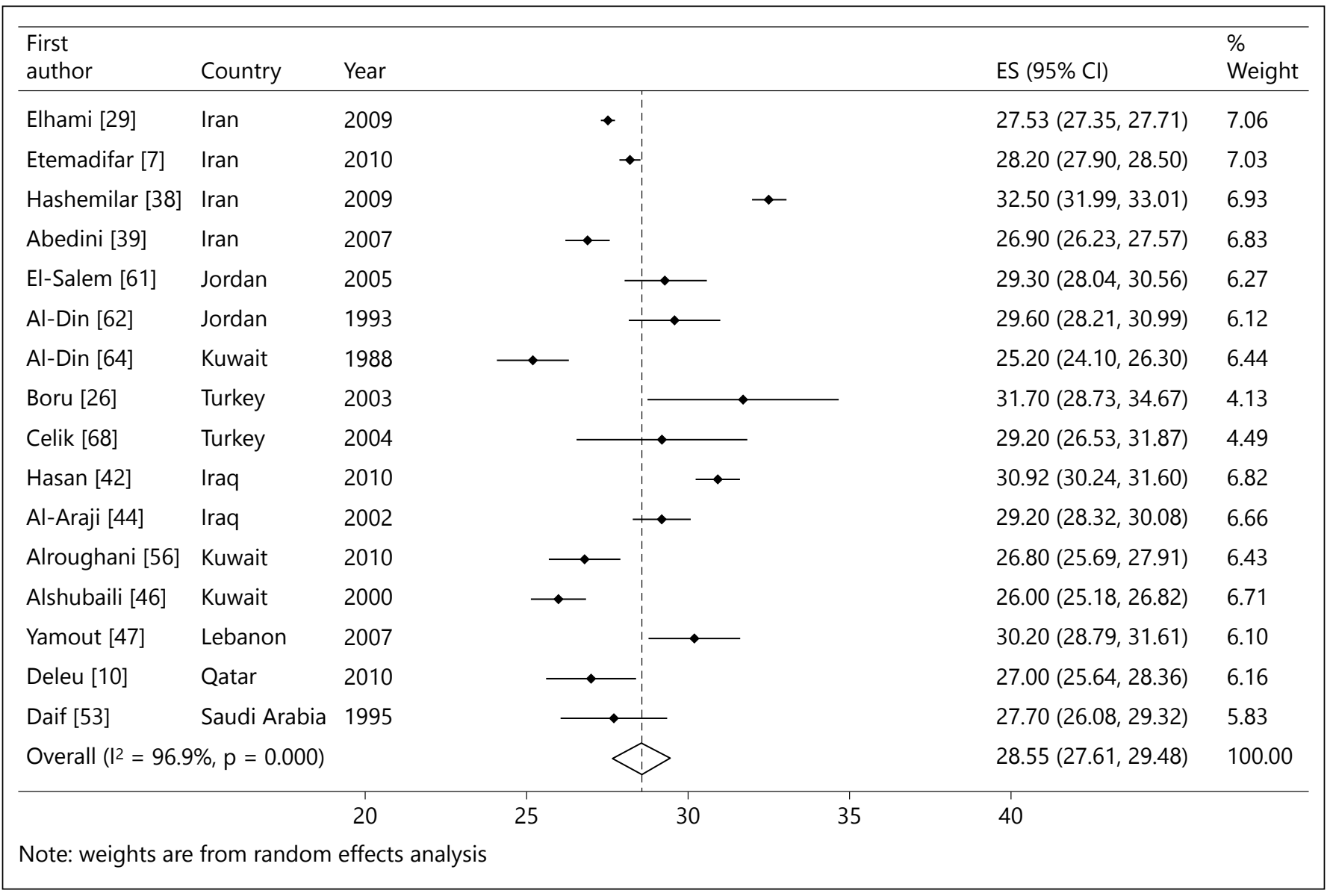

Fig. 4. The mean age at MS onset of studies in Middle East and North Africa.

Table 4. Meta-analysis of MS subtype proportion estimates

\begin{tabular}{|c|c|c|c|c|c|c|c|}
\hline MS subtype proportions & Pooled estimate & Lower limit & Upper limit & Heterogeneity statistic & Degrees of freedom & $\mathrm{p}$ value & $\mathrm{I}^{2}, \%$ \\
\hline RRMS & 0.74 & 0.71 & 0.77 & 578.27 & 32 & 0.000 & 94.5 \\
\hline SPMS & 0.12 & 0.10 & 0.15 & $1,250.50$ & 30 & 0.000 & 97.6 \\
\hline RPMS & 0.06 & 0.02 & 0.10 & 97.00 & 29 & 0.000 & 70.1 \\
\hline
\end{tabular}

lowed by sensory symptoms (19.9\%), visual symptoms (15.9\%), and ataxia (15.8\%). $73.45 \%$ of these patients had a relapsing-remitting course, primary-progressive course was seen in $17 \%$ of patients, and $9.55 \%$ had the secondary-progressive course.

\section{Iran}

The MS prevalence in Tehran has increased from $51.9 / 100,000$ in 2008 to $74.28 / 100,000$ in 2011 . The annual MS incidence has significantly increased over the last two decades from 0.68 (1989) to the peak of 5.68/ 100,000 (2005). The disease was almost 3 times more common in females than in males. RRMS was recognized in $84.9 \%$ of patients. The mean age at disease onset was 27.24 years; there was a positive family history of MS in $9.5 \%$ of the patients $[8,29,30]$.

Population-based studies in Isfahan have revealed a general increase in MS prevalence and incidence over a decade, the MS prevalence has increased from 35.5 in 2006 to 85.8 per 100,000 in 2013, with an incidence of 9.1 
in 2009. Similar to Tehran, a female to male ratio of 3.37 was seen with a family history of MS in $12.2 \%$ of patients. The clinical course of MS was RRMS in $87.8 \%$, SPMS in $6.4 \%$, and PPMS in $5.7 \%$ of patients. The initial presentation was sensory in $51.7 \%$, and visual disturbances were seen in $47.5 \%$ of patients. Early and late onset MS was seen in 5 and $1.1 \%$ of patients, respectively, and the mean age at disease onset was 28.2 years [ $7,9,28,31,70]$.

Variable prevalence rates have been reported from other regions in Iran, prevalence rate was 20.1 per 100,000 in Mazandaran (North Iran) [39], 27.7 in East Azerbaijan (Northwest Iran) [38], 16.28 in Khuzestan (Southwest Iran) [36], 13.96 in Sistan and Balouchestan (Southeast Iran) [71], and ranging from 5.3 to 12.9 in Khorasan (Northeast Iran) [32]. A higher prevalence of MS was seen in central provinces of Qom (50.4) and Kerman (31.5), similar to reports from Tehran and Isfahan $[33,37]$.

\section{Iraq}

A progressive increase in MS prevalence and a trend toward more female patients was observed in Iraq in the last two decades. The initial symptom was reported as motor in $31.7 \%$, sensory in $28.3 \%$, optic nerve in $24 \%$ and brainstem or cerebellar in $22.3 \%$ of patients. The course was relapsing remitting in $66.3 \%$ patients, secondary progressive in $18.7 \%$, and primary progressive in $15 \%$ patients. However, a different medical care pattern among the male and female patients in Iraq resulted in a lower female to male gender ratio (1.2:1) compared to the western nations [44]. In another study, the mean age at clinically definite MS onset was 30.92 [42]; Hasan et al. showed that $6.8 \%$ of their patients attending an MS clinic in Iraq experienced MS symptoms before the age of 18 years [57].

\section{Jordan}

Jordan has been considered as an area of low to medium risk of MS, a 2-year hospital-based study on $126 \mathrm{MS}$ patients (1992-1993) reported a prevalence of 42/100,000 among patients with Palestinian origin, while the prevalence among patients with Jordanian origin was 20 [62, 63]. However, a more recent study reported a prevalence rate of 39/100,000 in the city of Amman and 38 in Irbid, regardless of the origin of the ancestors. Fifty-seven new cases were diagnosed in the study year, resulting in an incidence of $1.14 / 100,000$. The mean age of onset was 29.3 years. The most common clinical presentation was weakness $(30.8 \%)$, followed by optic neuritis $(20.1 \%)$, sensory impairment (19.6\%), and ataxia (14.3\%). A positive family history of MS was found in $9.4 \%$ of the cases [61].

MS Epidemiology in Middle East and North Africa

\section{Kuwait}

Alshubaili et al. reported that the MS incidence rate has increased from 1.05 in 1993 to 2.62/100,000 in 2000. An increasing pattern was also observed in the prevalence rates $(6.68 / 100,000$ at the end of 1993 to $14.77 / 100,000$ by 2000). The estimated prevalence was markedly higher for Kuwaitis (31.15) than for non-Kuwaitis (5.55) [46]. Najim Al-Din et al. found a statistically different prevalence rate among Kuwaitis (9.5) and Palestinians (23.8) resident in Kuwait. The most common symptom at diagnosis were sensory (52.4\%) and motor weakness (50.0\%), followed by unilateral optic neuritis (32.5\%), ocular palsy (25.7\%), and cerebellar signs (24.6\%) [64]. A more recent study reported an 85.05/100,000 crude prevalence rate of MS in Kuwait in 2011, with a higher prevalence in women [11].

\section{Lebanon}

Based on the Lebanese ministry of health records, total number of MS patients is estimated to be between 1,200 and 1,700. The most frequent presenting symptoms were brainstem-cerebellar (46.2\%), followed by sensory (42.5\%), motor (33.9\%), and visual (29.6\%). RRMS was seen in $85.1 \%$ of patients at onset, and $7.9 \%$ had PPMS. The female patients outnumbered males with a female to male ratio of $1.8: 1$. The mean age at onset of disease was 30.2 years. A positive family history of MS was reported by $5 \%$ of patients; however, Sawaya and Kanso found $30 \%$ of their group of patients had a first- or second-degree relative diagnosed with MS [47, 48].

\section{Libya}

The sole study on MS epidemiology in Libya dates back to 1985, where MS cases were detected yielding a crude prevalence rate of 4 per 100,000 and the age-adjusted prevalence rate of 5.9/100,000. A high prevalence of brainstem involvement and cerebellar dysfunction was seen in this study [65].

\section{Oman}

Oman has the lowest reported MS occurrence in the Arabian Peninsula; however, the MS prevalence has increased from 1.2/100,000 in 1996 to 4/100,000 in 2000. Among 30 patients with MS diagnosis, 23 patients had the relapsing-remitting course, 4 were secondary progressive, and 3 were primary progressive. Twelve patients presented with blurred vision, 6 with sensory symptoms, 5 with ataxia, 3 with diplopia, and 2 with hemiplegia [49]. 


\section{Qatar}

MS in Qatar is an emerging neurologic disorder; in the first epidemiological study of MS in Qatar, the crude prevalence was reported 64.57/100,000 (2010). The female/ male ratio (1.33:1) was remarkably lower than that observed in the remaining countries of the region. A positive family history was found in $10.4 \%$ of patients. The most common symptom at presentation was sensory manifestations, followed by optic neuritis or pyramidal symptoms [10]. In another study, 58.5\% patients had the RRMS disease course, $4.5 \%$ had SP, $2 \%$ had PP, and $7 \%$ had CIS.

\section{Saudi Arabia}

MS prevalence is low in Saudi Arabia $(25 / 100,000)$ [54]. The clinical course was relapsing remitting in $60.7 \%$, progressive relapsing in $20.2 \%$, and primary progressive in $19.1 \%$. The mean age at onset in Saudi patients (25.9 years) was lower than that of the non-Saudis (29.4 years). In the Saudi and non-Saudi group, the female/male ratio was $1.32: 1$ and $1.4: 1$, respectively. Weakness was the most common presenting symptom in both the Saudi and non-Saudi patients, followed by sensory impairment [53].

\section{Sudan}

Only 35 patients were seen during one decade in a central-tertiary specialized neurology center in Sudan. The most common presentation was paralysis of one or more extremities (68.6\%), followed by optic neuritis (37.1\%), cerebellar ataxia (11.4\%), and diplopia (5.7\%). The relapsing-remitting course was seen in $56 \%$ of patients, secondary progressive in $32 \%$, and $9 \%$ had the primary-progressive course [66].

\section{Tunisia}

In a multicenter hospital-based study conducted in Tunisia, 437 MS patients were included. Their disease course was relapsing remitting in $91 \%$ of patients and primary progressive in $9 \%$. The most frequent symptoms at onset were motor $(28 \%)$, optic neuritis $(20 \%)$, and sensory (16\%) dysfunction [67].

\section{Turkey}

MS prevalence in urban Istanbul $(101.3 / 100,000)$ was nearly more than twice the prevalence in rural regions of Northern Turkey: Kandira (61/100,000), Geyve (41/ 100,000), Erbaa (53/100,000), and Caucasus (68.97/ $100,000)$ [25-27]. The previous MS prevalence rate from Edrine city was reported to be $33.9 / 100,000$ in 2003 [68].
Türk Börü et al. reported that the initial symptoms in $51.5 \%$ of subjects were sensory, brainstem-related signs (42\%), cerebellar signs (33\%), motor signs (30\%), optic neuritis (30\%), and sphincter disturbances (15\%) [27].

\section{United Arab Emirates}

The crude prevalence rate of MS in Dubai was 19.2 per 100,000 in the whole population, while in the Dubai native population was 54.77 . The annual incidence rate was $6.8 / 100,000$ during 2000-2007. Majority of Dubai native patients had the RRMS disease course (76.9\%), 10.6\% were SP, $7.8 \%$ were CIS, and $4.4 \%$ were RP. The mean age of onset was 26.6 years and the female/male ratio was 2.85:1. The most common symptom at presentation was motor $(72.78 \%)$, followed by sensory $(48.41 \%)$, cerebellar (19.96\%), and ocular (16.13\%) [55].

\section{Discussion}

Our systematic review yielded 52 studies on epidemiology of MS in the Middle East countries. Main findings are: (1) McDonald's criteria were the most widely used diagnostic criteria. (2) Most of the studies were conducted in single hospital-based centers. (3) The female/male ratio ranged from 0.8 (Oman) to 4.3 (Saudi Arabia). (4) The overall MS prevalencein the region was 51.52/100,000. (5) The mean age at disease onset ranged from 25.2 years (Kuwait) to 32.5 years (Northeastern Iran), with an overall estimate of 28.54 years.

The geographical distribution of MS patients has been the subject of numerous studies worldwide. Recent systematic reviews on the prevalence of MS in different regions of the world illustrate the changing epidemiology of disease and point to genetic and environmental disparities among these communities, leading to a global increase of MS. Reports from regions lacking sufficient epidemiological studies could be of particular importance in this regard. In this study, we tried to gather studies from the MENA countries.

Reports on MS prevalence with higher quality scores were derived from multicenter studies and regional registries in the capital or large cities within the country; nationwide studies were rare in the MENA countries. Higher quality scores of recent publications, and an increased prevalence in studies from the same areas over time, bring the conclusion of an increasing disease prevalence in the region.

Prevalence rates in our study ranged from 14.77/ 100,000 in Kuwait (2000) to 101.4/100,000 (Turkey). 
The role of latitude was underscored in a systematic review on MS incidence and prevalence in European countries. Estimates tended to be higher in the Northern regions of the United Kingdom and in the Nordic countries. The highest prevalence estimates in the Nordic region (over 200/100,000) were reported in Finland and Sweden [18].

A systematic review of studies on MS epidemiology in Americans reported a prevalence of 240/100,000 from a national health survey in Canada; the highest prevalence in US was reported from Olmstead County, Minn., USA $(191.2 / 100,000)$ [19]. A similar study in South America reported a prevalence rate ranging from 1.48 to 17 per 100,000 inhabitants in these countries [20].

The increase in disease prevalence in various MENA countries might be due to the western lifestyle changes in these countries. Smoking, sun protection products, low vitamin D levels, and environmental factors such as air pollution might be possible candidates.
This review has some limitations. The included studies are limited to publications in English. The lack of standardized age- and sex-specific estimates of prevalence data is an obstacle in combining studies from the same regions and comparing the changes over time. Strengths of the study included the comprehensive assessment of study quality and the independent data extraction by two reviewers.

\section{Conclusion}

The prevalence and incidence of MS are not well-documented in many countries of North Africa and Middle East. Although most prevalence estimates are derived from single hospital-based centers within a country, recent advances in MS registries will allow nation-wide studies. Temporal and spatial comparisons would be possible, provided that age- and sex-standardized estimates are available.

\section{References}

1 Dutta R, Trapp BD: Pathogenesis of axonal and neuronal damage in multiple sclerosis. Neurology 2007;68(suppl 3):S22-S31; discussion S43-S54.

2 Lublin FD, Reingold SC: Defining the clinical course of multiple sclerosis: results of an international survey. National multiple sclerosis society (USA) advisory committee on clinical trials of new agents in multiple sclerosis. Neurology 1996;46:907-911.

3 Noseworthy JH, et al: Multiple sclerosis. N Engl J Med 2000;343:938-952.

4 Koch-Henriksen N, Sørensen PS: The changing demographic pattern of multiple sclerosis epidemiology. Lancet Neurol 2010;9:520-532.

5 Orton SM, et al: Sex ratio of multiple sclerosis in Canada: a longitudinal study. Lancet Neurol 2006;5:932-936.

6 Browne P, et al: Atlas of Multiple Sclerosis 2013: A growing global problem with widespread inequity. Neurology 2014;83:10221024.

7 Etemadifar M, Maghzi AH: Sharp increase in the incidence and prevalence of multiple sclerosis in Isfahan, Iran. Mult Scler 2011;17: 1022-1027.

8 Heydarpour $\mathrm{P}$, et al: Multiple sclerosis in Tehran, Iran: a joinpoint trend analysis. Mult Scler 2014;20:512.

9 Etemadifar $\mathrm{M}$, et al: Multiple sclerosis in Isfahan, Iran: an update. Mult Scler 2013;20: 1145-1147.

10 Deleu D, et al: Prevalence, demographics and clinical characteristics of multiple sclerosis in Qatar. Mult Scler 2013;19:816-819.
11 Alroughani R, et al: Increasing prevalence and incidence rates of multiple sclerosis in Kuwait. Mult Scler 2014;20:543-547.

12 Ebers GC: Environmental factors and multiple sclerosis. Lancet Neurol 2008;7:268277.

13 Murray CJ, et al: Disability-adjusted life years (DALYs) for 291 diseases and injuries in 21 regions, 1990-2010: a systematic analysis for the global burden of disease study 2010 . Lancet 2012;380:2197-2223.

14 Poser CM, et al: New diagnostic criteria for multiple sclerosis: guidelines for research protocols. Ann Neurol 1983;13:227-231.

15 McDonald WI, et al: Recommended diagnostic criteria for multiple sclerosis: guidelines from the international panel on the diagnosis of multiple sclerosis. Ann Neurol 2001;50: 121-127.

16 Polman $\mathrm{CH}$, et al: Diagnostic criteria for multiple sclerosis: 2005 revisions to the 'McDonald criteria'. Ann Neurol 2005;58:840846.

17 Polman CH, et al: Diagnostic criteria for multiple sclerosis: 2010 revisions to the McDonald criteria. Ann Neurol 2011;69:292-302.

18 Kingwell E, et al: Incidence and prevalence of multiple sclerosis in Europe: a systematic review. BMC Neurol 2013;13:128.

19 Evans C, et al: Incidence and prevalence of multiple sclerosis in the Americas: a systematic review. Neuroepidemiology 2013;40: 195-210.

20 Cristiano E, Patrucco L, Rojas JI: A systematic review of the epidemiology of multiple sclerosis in South America. Eur J Neurol 2008; 15:1273-1278.

21 WHO: WHO Regions by LMIC, 2014. http:// www.who.int/phe/health_topics/outdoorair/ databases/country_grouping_May2014.pdf (cited April 17, 2015).

22 WHO: Analysis Categories and Mortality Data Sources, 2004. http://www.who.int/ healthinfo/global_burden_disease/GBD_ report_2004update_AnnexC.pdf?ua=1 (cited April 17, 2015).

23 The Joanna Briggs Institute: The Joanna Briggs Institute Reviewers' Manual: 2014 Edition/Supplement, 2014.

24 Tallawy HN, et al: Door-to-door survey of major neurological disorders (project) in $\mathrm{Al}$ Quseir City, Red Sea Governorate, Egypt. Neuropsychiatr Dis Treat 2013;9:767-771.

25 Recep ALP, Selen Ilhan ALP, Planci Y, Yapici Z, Börü UT: The prevalence of multiple sclerosis in the north Caucasus region of Turkey: door-to-door epidemiological field study. Nöropsikiyatri Arşivi 2012;49:272275.

26 Börü UT, et al: Prevalence of multiple sclerosis: door-to-door survey in three rural areas of coastal Black Sea regions of Turkey. Neuroepidemiology 2011;37:231-235.

27 Türk Börü U, et al: Prevalence of multiple sclerosis door-to-door survey in Maltepe, Istanbul, Turkey. Neuroepidemiology 2006; 27:17-21.

28 Etemadifar M, et al: Prevalence of multiple sclerosis in Isfahan, Iran. Neuroepidemiology 2006;27:39-44. 
29 Elhami SR, et al: A 20-year incidence trend (1989-2008) and point prevalence (March 20, 2009) of multiple sclerosis in Tehran, Iran: a population-based study. Neuroepidemiology 2011;36:141-147.

30 Sahraian MA, et al: Multiple sclerosis in Iran: a demographic study of 8,000 patients and changes over time. Eur Neurol 2010;64:331336.

31 Saadatnia $M$, Etemadifar M, Maghzi AH: Multiple sclerosis in Isfahan, Iran. Int Rev Neurobiol 2007;79:357-375.

32 Ghandehari K, et al: Prevalence of multiple sclerosis in north east of Iran. Mult Scler 2010 16:1525-1526.

33 Ebrahimi HA, Sedighi B: Prevalence of multiple sclerosis and environmental factors in Kerman province, Iran. Neurology Asia 2013; 18:385-389.

34 Saman-Nezhad B, et al: Epidemiological characteristics of patients with multiple sclerosis in Kermanshah, Iran in 2012. J Mazandaran Univ Med Sci 2013;23:97-101.

35 Majdinasab N, Nakhostin-Mortazavi A, Alemzadeh-Ansari MH: Epidemiologic features of multiple sclerosis in south-western Iran; in 28th Congress of the European Committee for Treatment and Research in Multiple Sclerosis. Lyon, France, 2012.

36 Sharafaddinzadeh N, et al: The influence of ethnicity on the characteristics of multiple sclerosis: a local population study between Persians and Arabs. Clin Neurol Neurosurg 2013;115:1271-1275.

37 Rezaali S, et al: Epidemiology of multiple sclerosis in Qom: demographic study in Iran. Iran J Neurol 2013;12:136-143.

38 Hashemilar M, Ouskui DS, Farhoudi M, Ayromlou H, Asadollahi A: Multiple sclerosis in east Azerbaijan, north west Iran. Neurology Asia 2011;16:127-131.

39 Abedini M, Habibi-Saravi R, Zarvani A, Farahmand M: Epidemiology of multiple sclerosis in Mazandran province in 2007 (in Persian). J Mazandaran Univ Med Sci 2008; 18:82-87.

40 Jajvandian R, Ali Babai A, Torabzadeh S Rakhshi N, Nikravesh A: Prevalence of multiple sclerosis in North Khorasan province, northern Iran; in $5^{\text {th }}$ Joint Triennial Congress of the European and Americas Committees for Treatment and Research in Multiple Sclerosis. Amsterdam, The Netherlands, 2011.

41 Hecham N: Descriptive epidemiology of MS patients followed in an Algerian University Hospital; in 26th Congress of the European
Committee for Treatment and Research in Multiple Sclerosis. Gothenburg, Sweden, 2010.

42 Hasan ZN: Disability and prognosis of relapsing remitting multiple sclerosis, is it different in Iraqi patients? Neurosciences (Riyadh) 2011;16:233-236.

43 Al-Hamadani HA, Abdalla AS, Al-Saffar AJ: The course of early-onset multiple sclerosis in Iraqi children. World J Pediatr 2012;8:47-51.

44 Al-Araji A, Mohammed AI: Multiple sclerosis in Iraq: does it have the same features encountered in Western countries? J Neurol Sci 2005; 234:67-71.

45 Bahou YG: Multiple sclerosis at Jordan University Hospital. Neurosciences (Riyadh) 2002;7:105-108.

46 Alshubaili AF, et al: Epidemiology of multiple sclerosis in Kuwait: new trends in incidence and prevalence. Eur Neurol 2005;53:125-131.

47 Yamout B, et al: Clinical characteristics of multiple sclerosis in Lebanon. J Neurol Sci 2008;270:88-93.

48 Sawaya RA, Kanso MI: Multiple sclerosis in Lebanon: a review of 45 cases. Mult Scler 2009; 15:279-280.

49 Tharakan JJ, Chand RP, Jacob PC: Multiple sclerosis in Oman. Neurosciences (Riyadh) 2005; 10:223-225.

50 Tharakan J, Chand P, Jacob PC: Multiple sclerosis in Oman: clinical and epidemiological study. J Neurol Sci 1997;150(suppl):S188.

51 Akhtar N, et al: Newly diagnosed multiple sclerosis in state of Qatar. Clin Neurol Neurosurg 2013;115:1333-1337.

52 Al-deeb S: Epidemiology of MS in Saudi Arabia; in 25th Congress of the European Committee for Treatment and Research in Multiple Sclerosis. Dusseldorf, Germany, 2009.

53 Daif AK, et al: Pattern of presentation of multiple sclerosis in Saudi Arabia: analysis based on clinical and paraclinical features. Eur Neurol 1998;39:182-186.

54 Yaqub BA, Daif AK: Multiple sclerosis in Saudi Arabia. Neurology 1988;38:621-623.

55 Inshasi J, Thakre M: Prevalence of multiple sclerosis in Dubai, United Arab Emirates. Int J Neurosci 2011;121:393-398.

56 Alroughani R, Ashkanani A, Lamdhade S: Clinical characteristics of multiple sclerosis in Kuwait: data from the new MS registry of Amiri Hospital. Int J Neurosci 2012;122:8287.

57 Hasan ZN, Hasan HA, Sabah AS: Clinical and radiological study of Iraqi multiple sclerosis patients with childhood onset. Neurosciences (Riyadh) 2011;16:229-232.

58 Hashem S, El-Tamawy M, Hamdy S, Elmasry T: Epidemiology of multiple sclerosis in Egypt. Egypt J Neurol Psychiatr Neurol 2010 47:625-632.

59 Kalanie H, Gharagozli K, Kalanie AR: Multiple sclerosis: report on 200 cases from Iran. Mult Scler 2003;9:36-38.

60 Al-Shimmery EK, Bzaini AS: Multiple sclerosis in Jordan and Iraq. Clinical and social overview. Neurosciences (Riyadh) 2008;13: 276-282.

61 El-Salem K, et al: Multiple sclerosis in Jordan: a clinical and epidemiological study. J Neurol 2006;253:1210-1216

62 al-Din AS, et al: Multiple sclerosis in Arabs in Jordan. J Neurol Sci 1995;131:144-149.

63 Najim Al-Din AS, et al: Epidemiology of multiple sclerosis in Arabs in Jordan: a comparative study between Jordanians and Palestinians. J Neurol Sci 1996;135:162-167.

64 al-Din AS, et al: Epidemiology of multiple sclerosis in Arabs in Kuwait: a comparative study between Kuwaitis and Palestinians. J Neurol Sci 1990;100:137-141.

65 Radhakrishnan K, et al: Prevalence and pattern of multiple sclerosis in Benghazi, northeastern Libya. J Neurol Sci 1985;70:39-46.

66 Idris MN, et al: Multiple sclerosis in Sudan: a prospective study of clinical presentation and outcome. Mult Scler 2009;15:1537-1538.

67 Sidhom Y, et al: Clinical features and disability progression in multiple sclerosis in Tunisia: do we really have a more aggressive disease course? J Neurol Sci 2014;343:110-114.

68 Çelik Y, Birgili Ö, Kiyat A, Güldiken B, Özkan H, Yilmaz H, Saip S, Kusçu D, Sütlas N, Agaoglu J, Utku U, Siva A: Prevalence of multiple sclerosis in the metropolitan area of Edirne City, Turkey. Balkan Med J 2011;28: 193-196.

69 Izadi S, et al: Significant increase in the prevalence of multiple sclerosis in Iran in 2011. Iran J Med Sci 2014;39:152-153.

70 Etemadifar M, et al: Epidemiology of multiple sclerosis in Iran: a systematic review. Eur Neurol 2013;70:356-363.

71 Moghtaderi A, Rakhshanizadeh F, ShahrakiIbrahimi S: Incidence and prevalence of multiple sclerosis in southeastern Iran. Clin Neurol Neurosurg 2013;115:304-308

72 Moghaddam AH, Iranmanesh F, Vakilian A: Epidemiology of multiple sclerosis in Rafsanjan: South of Iran. Multiple Sclerosis Journal, 2013. 